\title{
Rubisco turnover and its relationship with herbage yield traits in perennial ryegrass (Lolium perenne L.)
}

\author{
E.N. KHAEMBAH ${ }^{1}$, L.J. IRVING ${ }^{1}$, E.R. THOM ${ }^{2}$ and C. MATTHEW ${ }^{1}$ \\ ${ }^{\prime}$ Institute of Natural Resources, Massey University, PB 11222, Palmerston North \\ ${ }^{2}$ DairyNZ, PB 3221, Hamilton \\ e.n.khaembah@massey.ac.nz
}

\begin{abstract}
Leaf Rubisco content was monitored over the life span of the sixth leaf blades of hydroponically grown perennial ryegrass tillers of 18 genotypes, to determine protein turnover patterns and investigate possible links between protein turnover pattern and plant performance. Leaf Rubisco turnover was assumed to follow a log-normal distribution over time defined by three curve parameters; $d$-the peak height, $g$ - the timing of the peak, and $f$-the retention time. Highly significant differences among genotypes were observed for all three Rubisco turnover curve parameters. Principal component analysis of Rubisco turnover data with morphological and plant dry weight (DW) data indicated that Rubisco retention time tended to increase with increased leaf appearance interval, and that high DW plants tended to have a lower, earlier Rubisco peak with longer retention. These results must be regarded as tentative until confirmed by further study. Keywords: Rubisco, perennial ryegrass, remobilisation, dynamic model, mapping population
\end{abstract}

\section{Introduction}

Use of inorganic nitrogen $(\mathrm{N})$ fertiliser to overcome low soil $\mathrm{N}$ availability and to increase productivity has been linked to a range of environmental problems, in particular, eutrophication and damage to aquatic ecosystems (e.g. Raven \& Taylor 2003). The need to reduce the use of N fertiliser is urgent, but also a challenge, given the rising global food demand from population growth and rapidly changing consumer preferences (Kasha 1999). Plant breeding efforts, therefore, are now being directed at improving nitrogen use efficiency (NUE).

Internal recycling of $\mathrm{N}$ from senescing tissues is a major nutrient conservation mechanism, and represents the major $\mathrm{N}$ source for growth of new tissues (Lattanzi et al. 2005; Mae \& Ohira 1981; Peoples \& Dalling 1988). $\mathrm{N}$ taken up from the soil represents less than $40 \%$ of the $\mathrm{N}$ in new leaves, even when soil $\mathrm{N}$ is readily available. In most plant tissues, proteins represent the largest fraction of organic $\mathrm{N}$ which is potentially available for remobilisation during senescence. Rubisco (E.C.4.1.1.39), the photosynthetic enzyme, represents the major fraction of chloroplast $\mathrm{N}$ accounting for 15$30 \%$ of total leaf $\mathrm{N}_{\text {in }} \mathrm{C}_{3}$ plants (Evans 1989; Makino \& Osmond 1991). Therefore, understanding the regulation of Rubisco turnover is a logical first step to understanding the regulation of $\mathrm{N}$ cycling within the plant.

Rubisco concentration increases rapidly during leaf expansion, peaks around full leaf expansion and then declines slowly as the leaf ages (Mae et al. 1983). The products of its degradation during senescence are reutilised as an $\mathrm{N}$ source for developing tissues (Mae et al. 1983; Makino et al. 1984). The amount of Rubisco in the leaf is the result of a balance between its synthesis and degradation. The dynamic model developed by Irving \& Robinson (2006) describes the time course of leaf Rubisco content by a log-normal curve (Fig. 1).

Rubisco concentration at any time is a result of the

Figure 1 Log-normal model for time course of leaf Rubisco concentration proposed by Irving and Robinson (2006).

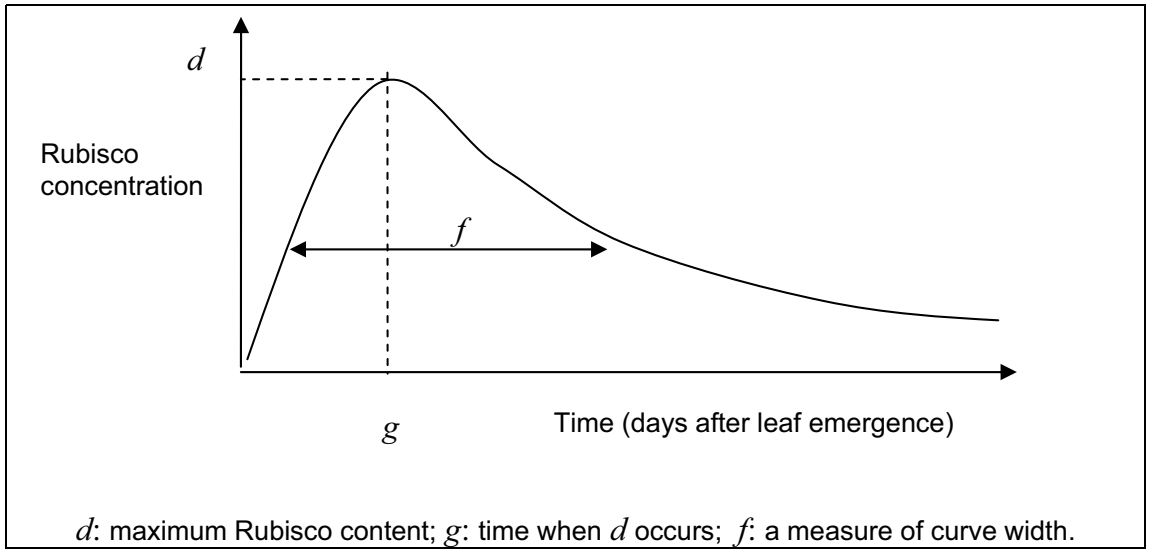


combined effect of synthesis and first order degradation. Curve parameters, $d, f$ and $g$, are determined by the underlying processes, which may differ between treatments or genotypes. A hypothesis underlying our work was that fast Rubisco degradation may lead to loss of photosynthetic potential late in the life span of a leaf, while slow Rubisco turnover may result in $\mathrm{N}$ being lost to the plant and not remobilised during leaf senescence. A proper balance between maintaining photosynthetic function and $\mathrm{N}$ remobilisation is expected to lead to high NUE and high yield.

To examine the relationship between Rubisco turnover and productivity traits in perennial ryegrass using a quantitative genetic approach, a three-phase study was established as follows: (1) development of Rubisco measurement methodology using barley leaves; (2) confirmation of the existence of genotype differences in Rubisco turnover in a perennial ryegrass population, and (3) determination of Rubisco turnover and QTL detection in plants of a ryegrass mapping population, the morphological characteristics of which have already been defined (Sartie 2006; Crush et al. 2007). This paper reports on phase 2. A subset of the mapping population comprising 18 genotypes of contrasting morphology was used with a view to not only confirming that differences exist between ryegrass genotypes in Rubisco turnover as defined by the Irving and Robinson model, but also providing indicative evidence as to whether particular patterns of Rubisco turnover can be associated with agronomically desirable traits.

\section{Materials and Methods}

\section{Plant material and growing conditions}

Eighteen perennial ryegrass (Lolium perenne L.) genotypes (one plant each from the cultivars Grasslands Samson and Grasslands Impact, and $16 \mathrm{~F}_{1}$ progeny of these two plants from a full-sib mapping population, $\mathrm{n}=$ 200 (Crush et al. 2007)) were selected based on differences in plant form and morphology determined by Sartie (2006). For the 16 progeny and their two parent plants, 16 uniform tillers per plant were obtained from subdivision of four plants and were grown hydroponically in a temperature controlled glasshouse (min. $15^{\circ} \mathrm{C}, \max .25^{\circ} \mathrm{C}$ ) at the Plant Growth Unit, Massey University. These 16 tillers of each of the 18 genotypes were grown on for several weeks until they had formed plants of about 10 tillers, and then two separate samples of leaves of differing ages were collected from each plant for Rubisco turnover determination. The stock nutrient solution consisted of $0.3 \mathrm{mM} \mathrm{NH} \mathrm{NO}_{3}, 0.6 \mathrm{mM} \mathrm{NaH} \mathrm{PO}_{4} \cdot \mathrm{H}_{2} \mathrm{O}, 0.6 \mathrm{mM}$ $\mathrm{MgCl}_{2} \cdot \mathrm{H}_{2} \mathrm{O}, 0.3 \mathrm{mM} \mathrm{CaCl}_{2} \cdot \mathrm{H}_{2} \mathrm{O}, 50 \mu \mathrm{M} \mathrm{H}_{3} \mathrm{BO}_{3}, 45 \mu \mathrm{M}$ Fe-EDTA, $9 \mu \mathrm{M} \mathrm{MnSO}_{4} .5 \mathrm{H} 2 \mathrm{O}, 0.7 \mu \mathrm{M} \mathrm{ZnSO} 4.7 \mathrm{H} 2 \mathrm{O}$, $0.3 \mu \mathrm{M} \mathrm{CuSO} 4.5 \mathrm{H} 2 \mathrm{O}, 0.1 \mu \mathrm{M} \mathrm{NaMoO}{ }_{4} .2 \mathrm{H}_{2} \mathrm{O}, 5 \mathrm{mM}$
MES dissolved in tap water. Additional nutrients were added weekly and the solution $\mathrm{pH}$ adjusted to 5.5 with $1 \mathrm{M} \mathrm{HCl}$. The amounts of nutrients added were increased with plant age. On days 4, 7, 11, 15, 22, 29, 36 and 41 after the sixth leaf had emerged (in different plants), it was excised from the plant at the leaf node, frozen, and stored until further analysis. In each sampling, three leaves per genotype were harvested.

\section{Determination of Rubisco}

Rubisco was determined as described by Takeuchi et al. (2002) with some minor modifications. Frozen leaves were thawed and homogenised in a $50 \mathrm{mM}$ sodiumphosphate buffer $(\mathrm{pH} 7.5)$ containing $0.8 \%(\mathrm{v} / \mathrm{v}) 2-$ mercaptoethanol, $2 \mathrm{mM}$ iodoacetic acid and $5 \%(\mathrm{v} / \mathrm{v})$ glycerol at a leaf buffer ratio of 1:5 (g:ml) in a chilled mortar and pestle. LDS $(2 \mu \mathrm{l})$ was added and the samples boiled at $100^{\circ} \mathrm{C}$ for $3 \mathrm{~min}$, then centrifuged at $10,000 \mathrm{xg}$ at $4{ }^{\circ} \mathrm{C}$ for $15 \mathrm{~min}$. The supernatant (LDS-soluble fraction) was stored at $-20^{\circ} \mathrm{C}$ until the determination of Rubisco content by SDS-PAGE. The amount of Rubisco was determined spectrophotometrically after formamide extraction of the Coomasie brilliant blue R-250 stain from the Rubisco bands on the gel as described in Makino et al. (1986), using bovine serum albumin standards (Seikagaku Co., Tokyo, Japan). Curve parameters $d, f$ and $g$ were determined in Sigma plot (version 10) using non-linear regression.

\section{Statistical analysis}

Rubisco turnover determinations for independent leaf samples of each genotype were treated as independent replicates, and ANOVA to determine genotype differences for curve parameters was performed in SAS (SAS Institute, Cary, North Carolina) using a completely randomised design model. Curve parameters averaged across the three replicates for each genotype were combined with morphology and growth data for those genotypes obtained in a previous series of experiments (Sartie 2006). Correlation coefficients were determined, and the data further analysed by principal component analysis (PCA) using the covariance matrix method of Minitab version 10.51 (Minitab Inc., State College, Pennsylvania), to test for associations between Rubisco turnover parameters and genotype morphology. Interpretation of PCs was based on size and sign of their coefficients and on inspection of PC scores for each genotype.

\section{Results and Discussion}

This work was essentially a "proof of concept" experiment on a small subset of a larger mapping population created for marker assisted selection work. For a number of reasons, including the possibility of genotype by 
Table 1 Genotype effects on Rubisco turnover curve parameters for 18 plant genotypes (two parent plants of an AgResearch perennial ryegrass mapping population and 16 of their $F_{1}$ progeny). Data are the values for the two parents, and the range of genotype means and their SEM.

\begin{tabular}{lccccc}
\hline Curve parameter & P1 & P2 & Progeny range & SEM & P value \\
\hline d; curve height (mg Rubisco-N/leaf) & 0.24 & 0.40 & $0.12-0.43$ & 0.011 & $<0.0001$ \\
f; curve width & 0.86 & 1.03 & $0.81-1.40$ & 0.067 & 0.0004 \\
g; time of curve peak (days) & 8.0 & 13.5 & $7.96-16.32$ & 0.761 & 0.0001 \\
\hline
\end{tabular}

P1 and P2 indicate values for the two parent plants, from Samson and Impact, respectively.

Table 2 Correlations between Rubisco curve parameters $d$, $f$, and $g$ determined in the present experiment, and the morphological traits measured in earlier experiments by Sartie (2006). Correlation coefficients of absolute value less than 0.25 (approx. $\mathrm{P}=0.2$ ) are suppressed. For the correlation of TW with $d$, $\mathrm{P}=0.013$.

\begin{tabular}{lcccccccc}
\hline RT & LER & LED & ALg & ALf & LL & TN & TW & DW \\
\hline$d$ & - & - & - & - & -0.27 & 0.40 & -0.57 & -0.28 \\
$f$ & -0.27 & 0.46 & - & 0.36 & - & - & - & - \\
$g$ & - & - & - & - & - & - & - & -0.33 \\
\hline
\end{tabular}

$\mathrm{RT}=$ Rubisco turnover curve parameter as defined in Fig. 1; LER = Leaf elongation rate; LED = Leaf elongation duration; $\mathrm{ALg}=\mathrm{Ligule}$ appearance rate; $\mathrm{ALf}=\mathrm{Leaf}$ appearance rate; $\mathrm{LL}=\mathrm{Leaf}$ length; $\mathrm{TN}=$ Tiller number; $\mathrm{TW}=$ Tiller weight, $\mathrm{DW}=\mathrm{Plant}$ dry weight.

Table 3 Principal component structure for the first five PCs of a total of 11 available from analysis of the 18 perennial ryegrass genotypes. Coefficients less than 0.15 contribute little to PC scores and are suppressed.

\begin{tabular}{|c|c|c|c|c|c|}
\hline Parameters ${ }^{1}$ & $\mathrm{PC} 1$ & PC2 & PC3 & PC4 & PC5 \\
\hline $\begin{array}{l}d \\
f\end{array}$ & $\begin{array}{l}-0.18 \\
-0.17\end{array}$ & $\begin{array}{l}-0.33 \\
0.32\end{array}$ & $\begin{array}{c}-0.42 \\
0.17\end{array}$ & $\begin{array}{l}-0.17 \\
0.61\end{array}$ & - \\
\hline$g$ & - & 0.20 & -0.42 & 0.58 & -0.31 \\
\hline LL & 0.15 & 0.50 & -0.18 & -0.38 & -0.30 \\
\hline LER & 0.37 & - & -0.27 & - & -0.53 \\
\hline LED & -0.43 & 0.30 & - & - & - \\
\hline ALf & -0.43 & 0.28 & - & -0.17 & - \\
\hline$A L g$ & -0.41 & 0.24 & -0.22 & -0.23 & - \\
\hline TN & -0.35 & -0.37 & - & - & -0.45 \\
\hline TW & 0.31 & 0.37 & 0.29 & - & 0.22 \\
\hline DW & - & - & 0.61 & - & -0.52 \\
\hline \% Var. (Eig.) & $36(3.9)$ & $22(2.4)$ & $16(1.7)$ & $11(1.1)$ & $7(0.8)$ \\
\hline
\end{tabular}

${ }^{1} d, f \& g=$ Rubisco turnover curve parameters as defined in Fig. 1. $L L=$ Leaf length, LER = leaf elongation rate, $L E D=$ leaf elongation duration, $\mathrm{ALf}=\mathrm{Le}$ eaf tip appearance interval, $\mathrm{ALg}=$ Leaf ligule appearance interval, $\mathrm{TN}=$ tiller number per plant, $\mathrm{TW}=$ mean tiller dry weight, DW $=$ Plant dry weight, $\%$ Var $=\%$ data variation associated with each PC, Eig = Eigenvalue.

environment interactions when using data from earlier experiments of Sartie (2006) in conjunction with the current data, all findings need to be treated as tentative, until confirmed by follow-up work with a larger number of genotypes. However, the authors believe the logic behind the research, and the preliminary results will be of interest to other workers in the field, and to extension workers and farmers as an indication of the potential role of science in forage grass improvement.

\section{Genotypic differences in Rubisco turnover}

There was a wide range of values for the curve parameters with progeny showing transgressive segregation (Table 1). An analysis of variance (ANOVA) indicated significant $(\mathrm{P}<0.001)$ differences among the genotypes for all curve parameters. Leaves of the plant from Grasslands Impact had a significantly $(\mathrm{P}<0.001)$ higher and later Rubisco peak than the plant from Grasslands Samson. The mapping population parents did not differ significantly in curve width.

Rubisco turnover, plant morphology and growth Only the correlation of tiller weight with curve height was statistically significant $(\mathrm{P}<0.05)$, though several other pair wise correlations approached significance, including the correlation $(\mathrm{P}=0.057)$ between leaf elongation duration and curve width (Table 2). Plants with a higher Rubisco peak tended towards a faster 
degradation ( $\mathrm{R}=0.273$ for $d$ and $f)$ and plants with a later peak tended towards a slower degradation $(\mathrm{R}=0.274$ for $g$ and $f$ ), although these two relationships were not statistically significant.

PC1 and PC2 (Table 3), between them accounting for $58 \%$ of the data variation, essentially reflect correlations among the morphological variables (Sartie 2006) and indicate two alternative strategies whereby a grass plant may form a heavier tiller or a longer leaf; through higher leaf elongation rate (PC1), or through increased leaf elongation duration (PC2). In both PC1 and PC2 there is a strong size/density compensation component indicated by the opposite signs for TN and TW (Table 3). Interestingly, the Samson and Impact parent plants of the mapping population are strongly separated in their scores for PC1, reflecting their contrasting morphology, whereas they both have similar scores for PC2. Rubisco turnover pattern is only very weakly linked with PC1, if at all. PC2 has superficially stronger links to the curve parameters (coefficients for $d, f$, and $g$ are $-0.33,0.32$, and 0.20 , respectively; Table 3 ). This pattern of association appears to be linked to the near significant correlation between leaf elongation duration and curve width noted in Table 2. A later Rubisco peak with increased leaf elongation duration is intuitively logical, since leaf expansion continues for a longer period. If longer LED and ALf were not accompanied by parallel increases in Rubisco turnover time, then it is likely there would be negative implications for plant performance.

PC 3 representing $16 \%$ of the data variation (Table 3 ) is the first of the PCs to have a substantive association with DW. While this is a lower order PC, it is not unusual in this kind of data set for a "size" PC to dominate the analysis, relegating more interesting "functional" relationships to a lower order. Based on coefficients for PC3 in Table 3, plants with increased DW tend towards a lower, earlier peak in leaf Rubisco concentration, with an increased curve width or retention time. The association between high DW and lower $d$ is counter-intuitive, but consistent with the possible negative correlation between $d$ and $f$ referred to above.

PC4 is shown by inspection of PC scores to arise from a very long Rubisco retention time in one particular genotype and hence does not represent a general relationship among the 18 genotypes tested. Since long Rubisco retention time could potentially interfere with $\mathrm{N}$ recycling from aging leaves to developing leaves, there is a logical reason why such genotypes would not necessarily be high yielding. The genotype in question in fact had a DW near the average for the 18 genotypes tested.

PC5 would normally be considered too small to be interpreted, but is included here because it is the first PC among 11 available to indicate any link between increased
LER and increased DW. That LER could not be strongly linked to genotype differences in DW or Rubisco turnover in this study is of interest because the link between increased LER and increased DW has been established in a previous study of perennial ryegrass (Bahmani et al. 2000). More generally these results correlate well with wider perceptions about the relationship between photosynthesis and plant growth, which is known to be complex, rather than simple. For example Osaki et al. (1993) found that while high yielding crops (both genetically improved crops and $\mathrm{N}$-fertilised crops) always had more Rubisco per unit leaf weight than lower yielding crops, the crop growth rate expressed as $g$ per $g$ Rubisco did not vary systematically between higher and lower yielding crops and was frequently higher in lower yielding crops.

\section{Conclusion}

Perennial ryegrass plants within a population varied widely in leaf Rubisco turnover characteristics, but Rubisco turnover was not strongly linked to morphology or herbage yield traits in this experiment. On PCA of Rubisco turnover data for 18 genotypes with their morphological and plant DW data, $\mathrm{PC} 1$ and $\mathrm{PC} 2$ reflected shoot size/density compensation between genotypes within the experimental population but this relationship was not associated with any trend in plant dry weight. PC3 indicated that heavier plants tended to have an earlier, lower Rubisco peak and longer Rubisco retention. These findings require verification and further study.

\section{ACKNOWLEDGEMENTS}

We thank Dr Syd Easton of AgResearch for providing the experimental material; Mr. Mike Hickey (AgResearch) for his help in preparing the experimental plants, and L. Sylva, S. Ray and L. Taylor of Massey University Plant Growth Unit for the construction of the hydroponic system and care of the plants. This work was supported by the T.R. Ellett Agricultural Research Trust.

\section{REFERENCES}

Bahmani, I.; Varlet-Grancher, C.; Hazard, L.; Matthew, C.; Betin, M.; Langlais, A.; Lemaire, G.; Thom, E.R. 2000. Differences in tillering behaviour of long- and short-leaved perennial ryegrass cultivars under full light and simulated shade. Crop Science 40: 10951102.

Crush, J.R.; Easton, H.S.; Waller, J.E.; Hume, D.E.; Faville, M.J. 2007. Genotypic variation in patterns of root distribution, nitrate interception and response to moisture stress of a perennial ryegrass (Lolium perenne L.) mapping population. Grass and Forage Science 62: 265-273. 
Evans, J.R. 1989. Photosynthesis and nitrogen relationships in leaves of C-3 plants. Oecologia 78: 919.

Irving, L.J.; Robinson, D. 2006. A dynamic model of Rubisco turnover in cereal leaves. New Phytologist 169: 493-504.

Kasha, K.J. 1999. Biotechnology and world food supply. Genome 42: 642-645.

Lattanzi, F.A.; Schnyder, H.; Thornton, B. 2005. The sources of carbon and nitrogen supplying leaf growth. Assessment of the role of stores with compartmental models. Plant Physiology 137: 383-395.

Mae, T.; Ohira, K. 1981. The remobilization of nitrogen related to leaf growth and senescence in rice plants (Oryza sativa L). Plant and Cell Physiology 22: 10671074.

Mae, T.; Makino, A.; Ohira, K. 1983. Changes in the amounts of Ribulose bisphosphate carboxylase synthesized and degraded during the life-span of rice leaf (Oryza sativa L). Plant and Cell Physiology 24: 1079-1086.

Makino, A.; Mae, T.; Ohira, K. 1984. Relation between nitrogen and Ribulose-1,5-bisphosphate carboxylase in rice leaves from emergence through senescence. Plant and Cell Physiology 25: 429-437.

Makino, A.; Mae, T; Ohira, K. 1986. Colorimetric measurement of protein stained with Coomassie Brilliant Blue- $\mathrm{R}$ on sodium dodecyl sulfatepolyacrylamide gel-electrophoresis by eluting with formamide. Agricultural and Biological Chemistry 50:
1911-1912.

Makino, A.; Osmond, C.B. 1991. Effects of nitrogen nutrition on nitrogen partitioning between chloroplasts and mitochondria in pea and wheat. Plant Physiology 96: 355-362.

Osaki, M.; Morikawa, K.; Matsumoto, M.; Shinano, T.; Iyoda, M.; Tadano, T. 1993. Productivity of highyielding crops III. Accumulation of Ribulose-1,5bisphosphate carboxylase oxygenase and chlorophyll in relation to productivity of high-yielding crops. Soil Science and Plant Nutrition 39: 399-408.

Peoples, M.B.; Dalling, M.J. 1988. The interplay between proteolysis and amino acid metabolism during senescence and nitrogen reallocation. pp 181-217. In: Senescence and Aging in Plants. Eds. Nooden, L.D.; Leopold, A.C. Academic Press, San Diego.

Raven, J. A.; Taylor, R. 2003. Macroalgal growth in nutrient-enriched estuaries: a biogeochemical perspective. Water, Air and Soil Pollution: Focus 3: 726.

Sartie, A.M. 2006. Phenotypic assessment and quantitative trait locus (QTL) analysis of herbage and seed production traits in perennial ryegrass (Lolium perenne L.). $\mathrm{PhD}$ Thesis, Massey University.

Takeuchi, A.; Yamaguchi, T.; Hidema, J.; Strid, A.; Kumagai, T. 2002. Changes in synthesis and degradation of Rubisco and LHCII with leaf age in rice (Oryza sativa L.) growing under supplementary UV-B radiation. Plant Cell and Environment 25: 695706. 